University of Louisville

ThinkIR: The University of Louisville's Institutional Repository

\title{
Epidemiology and virulence of Clostridium difficile : an evolutionary perspective.
}

\author{
Lindsey E. Hastings
}

University of Louisville

Follow this and additional works at: https://ir.library.louisville.edu/honors

Part of the Biology Commons

\section{Recommended Citation}

Hastings, Lindsey E., "Epidemiology and virulence of Clostridium difficile : an evolutionary perspective." (2014). College of Arts \& Sciences Senior Honors Theses. Paper 87.

http://doi.org/10.18297/honors/87

This Senior Honors Thesis is brought to you for free and open access by the College of Arts \& Sciences at ThinkIR: The University of Louisville's Institutional Repository. It has been accepted for inclusion in College of Arts \& Sciences Senior Honors Theses by an authorized administrator of ThinkIR: The University of Louisville's Institutional Repository. This title appears here courtesy of the author, who has retained all other copyrights. For more information, please contact thinkir@louisville.edu. 


\title{
Epidemiology and Virulence of Clostridium difficile: an Evolutionary Perspective
}

\author{
By: Lindsey E. Hastings
}

Submitted in partial fulfillment of the requirements for Graduation Summa cum laude

University of Louisville

$$
\text { May } 2014
$$




\begin{abstract}
The emergence of virulent, antibiotic-resistant Clostridium difficile ribotypes over the past thirty years has greatly concerned both the medical and research communities. As of 2010, C. difficile has surpassed methicillin-resistant Staphylococcus aureus (MRSA) as a cause of nosocomial infections and is now found in both healthcare settings and outside communities in the United States. Attendant-borne transmission in hospitals has been associated with the evolution of increased virulence in other nosocomial pathogens, but evolutionary theory has yet to be applied to the epidemiology and virulence of $C$. difficile. Differences between nosocomial C. difficile infections (CDI) and community-associated CDI (CA-CDI) mortality and ribotype distributions were evaluated in order to determine if attendant-borne transmission in hospitals and long-term care facilities favors highly virulent $C$. difficile ribotypes. Analysis of the current literature on $C$. difficile revealed that nosocomial CDIs were significantly more virulent and associated with greater mortality than CA-CDIs. Additionally, the data indicate that ribotypes 027 and $001 / \mathrm{smz}$ are particularly well-adapted for transmission in healthcare settings given their prominent role in nosocomial CDI but near absence in healthy $C$. difficile carriers in the outside community. These findings suggest that interventions that prevent attendant borne transmission may aid in the incidence reduction and virulence modification of $C$. difficile infections.
\end{abstract}

\title{
INTRODUCTION
}

\section{Nosocomial Infections and Attendant-Borne Transmission}

Nosocomial infections are a major contributor to morbidity and mortality globally. The World Health Organization estimates that 7 out of every 100 hospitalized patients in developed countries, and 10 out of every 100 in developing countries will contract at least one healthcare-associated infection (HAI) during the course of their stay (WHO 2013). In the United States, nosocomial infections were diagnosed in 
over 1.7 million people and associated with nearly 100,000 deaths in 2002 (Klevens, Edwards et al. 2007). Nosocomial infections are generally transmitted by attendants, such as doctors and nurses, who transfer the causal pathogens to infected patients on hands and gloves directly or indirectly through contamination of materials and equipment (i.e. fomites) in the hospital environment (Jameson et al. 1954, Knittle et al. 1975).

Evolutionary theory suggests that such attendant-borne transmission will favor evolution of increased virulence. The movement of attendants from one patient to another allows patients immobilized by severe illness to infect large numbers of other patients by way of attendants' contaminated hands. Consequently, highly exploitative pathogens can proliferate more extensively in environments that favor attendant-borne transmission and hence achieve an evolutionary fitness advantage over milder variants (Ewald 1988, Ewald 1991). In the outside community, infected hosts generally must move into contact with new hosts. This sort of transmission favors mildly exploitative organisms that do not significantly incapacitate their hosts. Accordingly, very sick, immobilized individuals cannot serve as a source of extensive transmission in the outside community.

Persistence in the environment outside of a host is also thought to favor the evolution of increased virulence by augmenting a pathogen's ability to be transmitted very sick infected hosts (Walther and Ewald 2004). Such "sit and wait" organisms have relatively low associated fitness costs with exploiting the host to the point of immobilization and even death because the organism can persist on a contaminated surface or on the host's body and still be transmitted via the movement of uninfected individuals in the contaminated environment. Accordingly, persistence in the environment can enhance attendant-borne transmission by increasing possibilities for transmission via fomites.

Several attendant-borne pathogens are known to cause severe disease in hospital settings (Ewald 1991, Cooper et al. 1999, Harbarth et al. 2003), including Staphylococcus aureus (Shinefield 1976), nontyphoid Salmonella (Mushin 1948, Rubbo 1948, Mackerras and Mackerras 1949), and Escherichia coli (Jacobs et al. 1970, Boyer et al. 1975). Studies of E. coli in neonates at a Cincinnati hospital found that infections were less severe when they were derived from mothers who had been infected outside the hospital 
as opposed to during their hospital stay (Cooper et al. 1956). Similar trends are seen in cases of non-typhoid Salmonella; infections acquired outside of hospitals or in situations where attendant-borne transmission plays a minimal role are rarely lethal (Kohler 1964), but hospital outbreaks are often severe and deadly (Ewald 1988). Attendant-borne transmission of non-typhoid Salmonella in Australian hospitals during 1946 and 1947 resulted in mortality rates of 15\% and 38\% respectively (Mushin 1948, Rubbo 1948, Mackerras and Mackerras 1949) whereas the case mortality rate is usually <1\% in developed countries (Chimalizeni et al. 2010).

These associations accord with the hypothesis that attendant-borne transmission in healthcare facilities favors increased virulence, but a direct comparison of virulence in attendant-borne strains relative to community strains has not, to my knowledge, been presented. The increasingly detailed understanding of nosocomial Clostridium difficile and the recent reports of hypervirulent strains makes it a highly-relevant candidate for such comparisons.

\section{Epidemiology of Clostridium difficile}

Clostridium difficile is a gram-positive, bacillus bacterium well-known for causing nosocomial infections of the intestinal tract in healthcare settings. One commonly accepted model of $C$. difficile infection, pathogenesis, and transmission involves recent host exposure to antibiotics, which supposedly leads to dysbiosis (i.e. microbial imbalance) and compromises the colonization barrier, resulting in infection with either endogenous or exogenous $C$. difficile. Symptomatic and asymptomatic infections cause shedding of $C$. difficile spores in the feces, which can persist on fomites and other surfaces and contaminate the hands of attendants (Bartlett 2006, Riggs et al. 2007, Deneve et al. 2009). A myriad of other associated risk factors for $C$. difficile infection (CDI) have been suggested in the literature, including hospitalization, old age ( $>65$ years), use of proton-pump inhibitors (PPIs), and comorbidities such as inflammatory bowel disease, although antibiotic exposure is considered to be the most important (Barbut et al. 1996, Jump et al. 2007, Deneve et al. 2009). The exact mechanism of dysbiosis and the true role of antibiotics in C. difficile colonization remains unclear. Antibiotics with very similar inhibitory spectra do not initiate CDI at the 
same rates; moreover, antibiotics associated with low disruption of the intestinal microbiota can be associated with CDI (Settle et al. 1998, Gerding 2004, Baines et al. 2005). Such findings suggest that additional mechanisms aside from disruption of the colonization barrier via the elimination of competing bacterial species may be playing an important role in $C$. difficile colonization (Settle et al. 1998, Baines et al. 2005).

C. difficile first began capturing the attention of the medical and scientific community in the late 1970s due to its role in cases of antimicrobial-associated diarrhea, colitis, and pseudomembranous colitis. Interest continued to grow once it was recognized as a cause of morbidity and mortality among hospitalized elderly patients (Freeman et al. 2010). The reported incidence of $C$. difficile-associated diarrhea (CDAD) rapidly grew in the United States from fewer than 150,000 cases in 2000 to an estimated 500,000 cases in 2006 (Redelings et al. 2007, Pamer 2013). Redelings et al. (2007) reported a 35\%-per-year increase in CDAD-related deaths between 1999 and 2004; over half of this increase was associated with an increase in the incidence of hospitalizations with severe infections (Redelings et al. 2007, Zilberberg et al. 2008). CDAD discharges from U.S. hospitals also doubled between 2000 and 2005 (Zilberberg et al. 2008). A 13year retrospective Canadian study of $C$. difficile infections (CDIs) reported an increase in incidence of 35.6 cases per 100,000 in 1991 to 156.3 cases per 100,000 in 2003 ; the 30 -day mortality rate of patients nearly tripled in this period from $4.7 \%$ to $13.8 \%$ (Pepin et al. 2004). In the Netherlands, deaths associated with CDAD or pseudomembranous colitis more than doubled from an age-standardized mortality rate of 11 per million population in 1999 to 24 per million in 2004 (Goorhuis et al. 2007, Freeman et al. 2010).

The growing problem of CDIs in the U.S., Canada, and England has been attributed in part to the emergence of highly virulent strains (McDonald et al. 2004, Pepin et al. 2004, Wilcox et al. 2012). C. difficile is a genetically diverse bacterial species with a common ancestor dating back to 1.1 to 85 million years ago, yet phylogenetic analysis has revealed that disease-causing $C$. difficile ribotypes are relatively new, with the epidemic 027 ribotype emerging only thirty years ago (He et al. 2010). Prior to 2000, highly virulent variants such as ribotype $027 / \mathrm{NAP} 1 / \mathrm{BI}$ accounted for $<1 \%$ of isolates collected in the United States 
(McDonald et al. 2005). During the first decade of the $21^{\text {st }}$ century, the 027 ribotype spread across most of the North America and Europe, with 16 European countries (Austria, Belgium, Denmark, Germany, Hungary, Finland, France, Ireland, Luxembourg, the Netherlands, Norway, Poland, Spain, Sweden, Switzerland, and the United Kingdom) reporting outbreaks by 2008 (Freeman et al. 2010). CDI mortality in Quebec was more than four times greater than for the rest of Canada combined; this increased mortality was thought to be due at least in part to ribotype 027, which was most frequently isolated in Quebec, Ontario, and British Columbia (Gravel et al. 2009). A study conducted in the U.S., representing 45 locations, 25 states, and 548 isolates collected between 2005 and 2007, found that ribotype 027 (which corresponds to restriction endonuclease analysis group BI) composed 54\% of the collection, was found in $80 \%$ of the states, and $82 \%$ of the individual hospitals (Cheknis et al. 2009). An earlier nation-wide study conducted during CDI outbreaks between 2000 and 2003 similarly found that $51 \%$ of isolates were ribotype 027 (McDonald et al. 2005). Japan also recorded a shift in their C. difficile ribotype population between 2000 and 2004 when the predominant ribotype isolated from CDI patients changed from a milder ribotype, known as ribotype a, to the more virulent epidemic strain, known as ribotype smz (Sawabe et al. 2007). This ribotype is thought to be synonymous with ribotype 001 (Freeman et al. 2010), which seems to have been slowly replacing ribotype 027 as of 2008 across 34 European countries (Bauer et al. 2009). Out of the 64 ribotypes identified in 7 hospitals sampled per country, ribotype 001 comprised $10 \%$ of isolates whereas 027 comprised 5\% (Bauer et al. 2009). Curiously enough, two lesser-known ribotypes, 014 and 020, accounted for $15 \%$ of the isolates (Bauer et al. 2009). Cheknis et al. (2009) found that ribotype 027's predominance has recently diminished in Europe, with only 3 out of 13 countries surveyed reporting it as the most common strain. They noted that ribotype 001 (their REA group J) was the most frequently isolated in Europe. Despite the recently observed changes in the epidemiology of $C$. difficile in Europe, ribotype 027 continues to persist as the predominant ribotype associated with CDI outbreaks in both Canada and the United States (Janezic et al. 2012). 
Interpretations of the overall trends in $C$. difficile virulence is complicated by the increasing antibiotic-resistance of some $C$. difficile strains, even to third generation cephalosporins and fluoroquinolones (Razavi et al. 2007). Moreover, treatment with fluoroquinolones has not only been demonstrated to be ineffective but also to enhance sporulation, vegetative cell growth, and toxin production in certain ribotypes, most notably 027 and 001 (Saxton et al. 2009). Clindamycin, which had previously been thought to be "protective" against CDI development, was rendered useless against certain 027 variants that were first reported in Switzerland in 2008 (Freeman et al. 2010). These changes in the epidemiology and pathology of $C$. difficile infections have been alarming for both the medical and research communities. As Voelker (2010) states, "During the past decade, mutations in the bacterium have transformed C. difficile from a rare nosocomial infection to one that can spread rapidly in hospitals and has spilled out into the community. Now infections of healthy individuals with few or no risk factors is not uncommon, and increasing recurrence rates have been reported." With a relapse and recurrence rate of 20\%, CDAD imposes a financial burden of nearly $\$ 1$ billion dollars in healthcare costs per year (Dubberke et al. 2008, Cohen et al. 2010). These health-related and economic consequences warrant greater attention with respect to the emergence and control of highly virulent pathogens.

This study evaluates a central prediction of the hypothesis that attendant-borne transmission favors increased virulence, namely that ribotypes of high virulence should be associated with transmission in healthcare settings. It assesses the extent to which Clostridium difficile ribotypes are transmitted in healthcare settings as opposed to in the outside community and whether any nosocomial ribotypes are more virulent than community ribotypes. Finally, it considers implications for the control of C. difficile-related illness. 


\section{ATTENDANT-BORNE TRANSMISSION, DURABILITY, AND VIRULENCE OF C. DIFFICILE}

\section{Circulation in Hospitals Relative to the Outside Community}

The transmission cycles of Clostridium difficile are only partially understood and are widely debated, leading to uncertainty and disagreement over the roles of healthcare institutions, healthcare personnel, and asymptomatic carriers in the spread of CDIs (Clabots et al. 1992, Samore et al. 1996, Settle et al. 1998, Riggs et al. 2007). Depending upon study parameters, some researchers narrowly classify nosocomial CDIs as those with a direct link to hospitals or long-term care facilities (LTCFs). Others define nosocomial CDIs more broadly to include healthcare contacts that occur during visits to a hospitals, LTCFs, and doctor's offices. To account for the variation in definitions, this paper will use the terms "broadly nosocomial" and "narrowly nosocomial" to clarify the origins of CDI when possible.

Hospitalization and residence in a LTCF are both known to be associated with an increased risk for narrowly nosocomial $C$. difficile infections, but the source of infection is often ambiguous unless extensive and rigorous strain typing and epidemiological tracking are implemented during outbreaks (Freeman et al. 2010). The increase in apparent community-associated CDAD over the past two decades has led some to suggest that transmission from individuals in the community may play an important role in introducing virulent $C$. difficile strains to hospitals and patients and that nosocomial transmission has been greatly overestimated (Khanna and Pardi 2010). However, a recent Centers for Disease Control and Prevention study concluded that $94 \%$ of symptomatic $C$. difficile infections could be traced back to hospitals or other healthcare settings despite the majority of infections (74\%) having symptom onset in the outside community (McDonald et al. 2012). An earlier prospective cross-over study of elderly patients in the United Kingdom also reported similar findings and concluded from DNA fingerprinting analysis that "most infections arose from strains acquired from the hospital environment" (Settle et al. 1998). Length of hospital stay has also been directly correlated with acquisition of $C$. difficile (Clabots et al. 1992, Riggs et al. 2007). These 
findings lend credence to the notion that hospitals and other healthcare facilities may inadvertently play a major role in transmission of $C$. difficile. The critical question, however, is whether the nosocomial strains are distinct from and inherently more virulent than the strains that cycle predominantly in the outside community.

A PCR ribotyping study on strains isolated during 1999-2000 from three hospitals in Örebro County, Sweden revealed one ribotype (SE17) that was especially well-suited for transmission in hospitals; it accounted for $26 \%$ of nosocomial-associated CDAD cases versus only $6 \%$ of community-associated cases (Norén et al. 2004). Similar findings were reported for ribotype 001 in the United Kingdom prior to the peak years of the ribotype 027 outbreaks. Nearly $55 \%$ of isolates from hospitals in the United Kingdom were identified as ribotype 001 whereas only $7.5 \%$ of community CDIs were attributable to 001 (Stubbs et al. 1999). It has been suggested that this particular ribotype has an increased attack rate or greater ability for nosocomial spread (Akerlund et al. 2006). The presence of this hospital-associated ribotype in the outside community indicates that the hospital-associated ribotypes can be found in the outside community but does not reveal the extent to which these ribotypes are cycling outside of hospital settings. If hospital settings favor highly virulent ribotypes, these may cycle back to the hospital relatively quickly because of their propensity for causing severe illness, which may lead to the hospitalization of infected individuals.

It has been proposed that asymptomatic carriers from the outside community could be introducing virulent strains of Clostridium difficile into hospital settings and could potentially be the source of some of the ribotypes that are typically healthcare-associated, such as PCR ribotype 027 (Clabots et al. 1992, Riggs et al. 2007, Sheth 2013). However a PCR ribotyping study conducted among 1234 healthy individuals in Japan challenges this hypothesis; it found that 94 of the participants (7.6\%) carried C. difficile. The isolates belonged to 37 different ribotypes, but none was $001 / \mathrm{smz}$, the most frequently recovered ribotype from CDAD patients in Japanese hospitals (Kato et al. 2001). These findings suggest that $C$. difficile is widespread among asymptomatic individuals in the outside community, but ribotype $001 / \mathrm{smz}$ is not particularly common in the community relative to healthcare settings. It has been posited that ribotype 
001/smz might have specific virulence factors that favor successful transmission in healthcare settings (Akerlund et al. 2006, Sawabe et al. 2007). A study of 149 healthy elderly individuals living in the United Kingdom discovered that $4 \%$ carried $C$. difficile (Miyajima et al. 2011). In accordance with the data from Japan, healthcare-associated ribotypes were under-represented. Ribotype 027 was not present among these asymptomatic carriers. Only one individual was colonized with ribotype 106, a strain responsible for several hospital outbreaks in the United Kingdom (Bauer et al. 2009, Freeman et al. 2010).

Conversely, several studies have noted much higher asymptomatic colonization rates among hospitalized patients and residents of LTCFs, even though their risk of developing CDAD was not significantly greater than that of other patients on the ward who were also treated with antibiotics (Clabots et al. 1992, Shim et al. 1998, Riggs et al. 2007). In fact, one study of new admissions to a hospital found that $21 \%$ were asymptomatically colonized with $C$. difficile and another study reported carriage rates of $51 \%$ in one LTCF (Clabots et al. 1992, Riggs et al. 2007). Clabots et al. (1992) noted that patients who had previously been hospitalized in the medical center during the 30 days prior to admission were more likely to be culture-positive for $C$. difficile than those who were not previously hospitalized at the institution (16\% vs. $7 \%, \mathrm{P}<0.001$ ), suggesting that many of these patients were colonized with $C$. difficile through past healthcare exposures. Patients hospitalized in the past 30 days also comprised $57 \%$ of asymptomatic carriers admitted to the ward (Clabots et al. 1992). Unfortunately the investigators did not include testing for nontoxigenic strains or strains that lacked either TcdA or TcdB in their methodology, so the actual C. difficile carriage rate may be even greater than $51 \%$. Of the toxigenic strains that were typed and carried by asymptomatic patients, 37\% were belonged to ribotype 027 (the NAP1 group referred to in their study). This figure contrasts starkly with the reported carriage rates of epidemic ribotypes among healthy asymptomatic carriers in both the Japan and the United Kingdom (Riggs et al. 2007). The presence of virulent ribotypes that are frequently associated with $C$. difficile outbreaks such as 027 and 001 in hospitals and LTCFs and their rarity in healthy individuals in the community who have few recent healthcare 
exposures suggests that a distinction between nosocomial ribotypes and community-associated ribotypes exists.

\section{Mortality and Morbidity of $C$. difficile in Nosocomial and Community Settings}

One method for assessing the virulence of $C$. difficile is to examine mortality differences between CDIs associated with nosocomial environments and those associated with the community. In the study conducted by Norén et al. in Sweden, mortality rates were significantly higher for narrowly nosocomialassociated CDAD than for community-associated CDAD ( $15 \%$ vs $4 \%$ respectively; $\mathrm{p}=0.02$ ) (Norén et al. 2004). Even when patients with severe comorbidity were omitted from the analysis, the mortality rate for the narrowly nosocomial-associated CDAD $(9 \%)$ was still significantly greater $(\mathrm{p}=0.04)$ than that of the community-associated $\operatorname{CDAD}(1.7 \%)$ as seen in Table 1 . Unfortunately the authors did not provide a breakdown of mortality by ribotype, meaning that associations between mortality and individual ribotypes that may be predominantly nosocomial or predominantly community-acquired could not be assessed. However the aggregate differences in comorbidity-adjusted mortality between hospital-associated and community-acquired ribotypes suggest that nosocomial ribotypes may in fact be more virulent and accord with the prediction that nosocomial $C$. difficile infections will be more severe in healthcare settings where attendant-borne transmission can occur.

\begin{tabular}{|c|c|c|c|}
\hline \multicolumn{3}{|c|}{ Table 1: Orebro County, Sweden CDAD Mortality } \\
\hline & Hospital-associated & $\begin{array}{c}\text { Community- } \\
\text { acquired }\end{array}$ & P-value \\
\hline Mortality & $15 \%$ & $4 \%$ & 0.02 \\
\hline $\begin{array}{c}\text { Mortality Adjusted } \\
\text { for Concomitant } \\
\text { Disease }\end{array}$ & $9 \%$ & $1.7 \%$ & 0.04 \\
\hline
\end{tabular}


Another epidemiological study of $C$. difficile conducted in Monroe County, New York (Dumyati et al. 2012) reported similar findings regarding the mortality of CA-CDI versus HA-CDI, as seen in Table 2. For the purposes of their study, the authors divided their participants into three groups based upon recent healthcare exposures: (i) healthcare facility onset CDI (contains patients who had a positive fecal test for C. difficile at least 48 hours after being admitted to a hospital or LTCF and corresponds with the healthcareassociated/narrowly nosocomial definition), (ii) community-onset healthcare-associated (CO-HCA) CDI which was preceded by prior admission in the past 12 weeks to a hospital or LTCF, and (iii) communityassociated CDI. If a distinction exists between $C$. difficile ribotypes circulating in hospitals and those in the community, patients with CO-HCA should share many of the same clinical characteristics with patients diagnosed with HA-CDI and should have fewer characteristics in common with patients diagnosed with CA-CDI. As seen in Table 2, mortality rates (which include only deaths directly attributable to CDI) between the HA-CDI group (3.5\%) and CO-HCA group (2.9\%) were not significantly different $(\mathrm{p}=0.2)$. However the CA-CDI group experienced no mortality, and when compared, the mortality rates in the CACDI group versus the nosocomial CDI group (HA-CDI plus CO HCA) were highly significant ( $\mathrm{p}=0.0017$ ). On average, patients with CO-HCA required hospitalization more frequently $(\mathrm{p}=0.02)$ and were hospitalized longer $(\mathrm{p}=0.03)$ than CA-CDI patients. The differences between these two groups accords with the prediction that nosocomial CDI will be more severe than CA-CDI. Recurrence rates were the same in the HA-CDI and CO-CDI group but were $10 \%$ lower for the CA-CDI group $(\mathrm{p}=0.17)$, but this was statistically insignificant given the parameters of this study (definitional differences and subsequent categorization of cases may play a role, as discussed later). Higher recurrence rates would be expected if nosocomial ribotypes are more virulent, but it could also be attributable to host health given the recent history of hospitalization or residence in a LTCF for the HA-CDI group. However, the mortality rates that were adjusted for comorbidities still demonstrated a difference in deaths attributable to HA-CDI, CO-CDI, and CA-CDI, which suggests that the $C$. difficile associated with CA-CDI are less virulent than those associated with nosocomial CDI. 


\begin{tabular}{|l|c|c|c|}
\hline \multicolumn{3}{|c|}{ Table 2: Monroe County, New York CDI } \\
\hline & $\begin{array}{c}\text { Healthcare-associated } \\
\text { (Narrowly nosocomial) }\end{array}$ & $\begin{array}{c}\text { Community-Onset } \\
\text { Healthcare-associated }\end{array}$ & Community-associated \\
\hline Cases & $196(54 \%)$ & $103(28 \%)$ & $67(18 \%)$ \\
\hline Mortality & $7(3.5 \%)$ & $3(2.9 \%)$ & 0 \\
\hline $\begin{array}{l}\text { Required } \\
\text { Hospitalization }\end{array}$ & N/A & $39(38 \%)$ & $13(19 \%)$ \\
\hline $\begin{array}{l}\text { Average Duration of } \\
\text { Hospitalization (days) }\end{array}$ & N/A & 7 & 3.5 \\
\hline Recurrence & $43(22 \%)$ & $23(22 \%)$ & $8(12 \%)$ \\
\hline
\end{tabular}

The higher proportion of CA-CDI reported in this study (18\%) relative to the aforementioned proportion of 6\% (McDonald et al. 2012) may reflect definitional differences because individuals who had come into contact with other healthcare facilities as outpatients, visited family members in a hospital or LTCF, or visited a doctor's office were included in the CA-CDI group. In fact, $83 \%$ of CA-CDI patients reported receiving healthcare at an outpatient office in the 12 weeks preceding the Monroe County study and $21 \%$ reported visiting a healthcare facility without receiving treatment (Dumyati et al. 2012).

Ratios of symptomatic to asymptomatic infections for community populations relative to hospital and LTCF populations can also indicate whether ribotypes circulating in a particular environment are more virulent than those in another. The symptomatic:asymptomatic infections ratio for patients in a LTCF was found to be 0.2 compared to a calculated ratio of $0.005(\mathrm{P}=0.001)$ given a $5 \%$ asymptomatic carriage rate reported by Akerlund et al. (2011) for healthy individuals in the outside community (Norén et al. 2004, Riggs et al. 2007). This difference suggests that nosocomial $C$. difficile ribotypes are indeed more virulent 
than community ribotypes, although estimates make it difficult to account for comorbidities that may make patients in nosocomial settings more susceptible to symptomatic infections.

\section{Durability and Virulence of $C$. difficile}

Evolutionary theory proposes that durability and attendant-borne transmission may contribute jointly to the evolutionary increases in pathogen virulence (see Introduction). A study of 4 hypervirulent (for the purposes of their experiment, defined as strains that had caused epidemics with greater incidence, severity, and mortality than non-hypervirulent strains) and 4 mild $C$. difficile strains found that the hypervirulent strains (all variants of ribotype 027 collected from various locations in the U.S. and Canada) sporulated earlier and produced more spores per total volume culture than mild strains (Merrigan et al. 2010). It was also noted that in general, the hypervirulent strains tended to sporulate with greater efficiency and also produced a robust amount of toxins (Merrigan et al. 2010). Another study of toxin production and spore-forming capabilities among several ribotypes, including the hospital and epidemic-associated ribotype 027 , found that 12 different isolates of 027 produced relatively large quantities of toxins and spores (Vohra and Poxton 2011). In a follow-up study comparing ribotypes 001, 012, 027, 087, and 106, it was observed that the epidemic 027 strain and two other prominent clinical strains - 001 and 106 - possessed superior spore-forming capabilities compared to the other milder strains (Vohra et al. 2012). Furthermore, it seems that environmental contamination of surfaces in healthcare settings with both spores and vegetative C. difficile is high, especially when CDAD patients and asymptomatic carriers are present (Fekety et al. 1981, Riggs et al. 2007, Sethi et al. 2010). Spores have been demonstrated to survive for up to 5 months on hospital surfaces (Kim et al. 1981). Such long persistence in the environment is likely to favor more virulent ribotypes, and not surprisingly, the highly virulent ribotype 027 along with the typically nosocomial ribotypes 001 and 106 all produced large numbers of spores. A general comparison of the spore-forming capabilities of several clinically-relevant strains is presented in Table 3. 


\begin{tabular}{|c|c|c|c|c|}
\hline Strain & $\begin{array}{l}\text { Epidemiological } \\
\text { Characteristics }\end{array}$ & $\begin{array}{c}\text { Toxin } \\
\text { Production }\end{array}$ & Sporulation & Antibiotic Resistance \\
\hline $\begin{array}{l}\text { Ribotype } 001 / \mathrm{smz} \\
\text { REA J } \\
\text { PFGE NAP2 }\end{array}$ & Frequently isolated in hospitals & $\begin{array}{l}\mathrm{A}+\mathrm{B}+ \\
\text { moderate }\end{array}$ & High & $\begin{array}{l}\text { Multidrug-resistant } \\
\text { Fluoroquinolone-resistant } \\
\text { (subtypes) } \\
\text { Fluoroquinolone-induced } \\
\text { virulence (subtypes) }\end{array}$ \\
\hline $\begin{array}{l}\text { Ribotype } 012 \\
\text { REA R } \\
\text { PFGE C7 } \\
\text { (ATCC 630) }\end{array}$ & $\begin{array}{l}\text { Rarely found in hospitals } \\
\text { presently }\end{array}$ & $\begin{array}{l}\mathrm{A}+\mathrm{B}+ \\
\text { moderate to } \\
\text { low }\end{array}$ & Low & $\begin{array}{l}\text { Multidrug-resistant } \\
\text { Tetracycline resistant }\end{array}$ \\
\hline $\begin{array}{l}\text { Ribotypes } 014 / 020 \\
\text { REA Y } \\
\text { PFGE: NAP4 }\end{array}$ & $\begin{array}{l}\text { Frequently isolated in hospitals } \\
\text { Found in livestock }\end{array}$ & $\mathrm{A}+\mathrm{B}+$ & $\begin{array}{l}\text { Spore-forming } \\
\text { (further study suggested) }\end{array}$ & Multidrug-resistant \\
\hline $\begin{array}{l}\text { Ribotype } 017 \\
\text { REA BK, CF, Y } \\
\text { PFGE NAP9 }\end{array}$ & Found in livestock & A-B + & $\begin{array}{l}\text { Spore-forming } \\
\text { (further study suggested) }\end{array}$ & Multidrug-resistant \\
\hline $\begin{array}{l}\text { Ribotype } 027 \\
\text { REA BI } \\
\text { PFGE NAP1 } \\
\text { (Epidemic 027) }\end{array}$ & $\begin{array}{l}\text { Frequently isolated in hospitals } \\
\text { and LTCFs } \\
\text { Found in the community } \\
\text { Found in livestock }\end{array}$ & $\begin{array}{l}\mathrm{A}+\mathrm{B}+\text { high } \\
t c d C \text { mutation } \\
\text { Produces } \\
\text { binary toxin }\end{array}$ & $\begin{array}{l}\text { High } \\
\text { Sporulate early }\end{array}$ & $\begin{array}{l}\text { Multidrug-resistant } \\
\text { Fluoroquinolone-resistant } \\
\text { Fluoroquinolone-induced } \\
\text { virulence } \\
\text { Clindamycin-induced } \\
\text { virulence }\end{array}$ \\
\hline $\begin{array}{l}\text { Ribotype } 027 \\
\text { REA BI-1 } \\
\text { PFGE NAP1 } \\
\text { (Non-epidemic) }\end{array}$ & Further study suggested & $\begin{array}{l}\mathrm{A}+\mathrm{B}+\text { high } \\
t c d C \text { mutation }\end{array}$ & Medium & $\begin{array}{l}\text { Multidrug-resistant } \\
\text { Fluoroquinolone-sensitive }\end{array}$ \\
\hline $\begin{array}{l}\text { Ribotype } 078 \\
\text { REA BK } \\
\text { PFGE NAP7 }\end{array}$ & $\begin{array}{l}\text { Found in hospitals } \\
\text { Found in CA-CDI } \\
\text { Found in livestock } \\
\text { Emerging strain }\end{array}$ & $\begin{array}{l}\mathrm{A}+\mathrm{B}+ \\
\text { binary toxin } \\
\text { (subtypes) }\end{array}$ & $\begin{array}{l}\text { Spore-forming } \\
\text { (further study suggested) }\end{array}$ & Multidrug-resistant \\
\hline $\begin{array}{l}\text { Ribotype } 087 \\
\text { REA Z3 } \\
\text { PFGE NAP12 } \\
\text { (ATCC VPI 10463) }\end{array}$ & $\begin{array}{l}\text { Rarely found in hospitals } \\
\text { Typically used as a reference } \\
\text { strain }\end{array}$ & $\mathrm{A}+\mathrm{B}+$ high & Low & Multidrug-resistant \\
\hline $\begin{array}{l}\text { Ribotype } 106 \\
\text { REA DH } \\
\text { PFGE NAP11 }\end{array}$ & $\begin{array}{l}\text { Frequently isolated in hospitals } \\
\text { (Epidemics in UK) }\end{array}$ & $\begin{array}{l}\mathrm{A}+\mathrm{B}+ \\
\text { moderate }\end{array}$ & Very high & $\begin{array}{l}\text { Multidrug-resistant } \\
\text { Clindamycin-induced } \\
\text { virulence }\end{array}$ \\
\hline \multicolumn{5}{|c|}{$\begin{array}{l}\text { Data for table compiled from Akerlund et al. 2008, Arvand et al. 2009, Freeman et al. 2010, Janezic et al. 2012, Keel et al. } 2007 \\
\text { Limbago et al. 2009, Merrigan et al. 2010, Saxton et al. 2009, Stabler et al. 2009, Sundram et al. 2009, Vohra et al. 2011, Vohra et al } \\
\text { 2012, Warny et al. 2005, Zidaric et al. 2012. }\end{array}$} \\
\hline
\end{tabular}




\section{RELEVANCE TO A UNIFIED UNDERSTANDING OF CLOSTRIDIUM DIFFICILE VARIATION, BIOLOGY \& PATHOLOGY}

\section{Attendant-borne Transmission \& Durability}

The increased mortality rates observed among nosocomial CDI and HA-CDAD patients relative to CA-CDI and CA-CDAD patients in both the Örebro County, Sweden and Monroe County, New York studies suggest that $C$. difficile ribotypes acquired from healthcare settings are indeed more virulent than community-associated ribotypes. Comparisons of ribotypes carried by healthy asymptomatic carriers in the outside community with few healthcare exposures with ribotypes carried by individuals exposed to healthcare settings revealed that ribotypes often responsible for severe outbreaks of CDI, such as ribotype 027 and 001/smz, were not frequently isolated from healthy individuals, but were very common in LTCFs and hospitals (Stubbs et al. 1999, Kato et al. 2001, Riggs et al. 2007, Sawabe et al. 2007, Miyajima et al. 2011). This suggests that nosocomial ribotypes may be distinct from community-associated ribotypes and likely possess virulence characteristics that make them well-adapted for transmission in healthcare settings (Akerlund et al. 2011). The presence of these typically nosocomial ribotypes in the outside community may reflect cycling, and such ribotypes would be expected to cause more severe cases that would garner medical attention and thus result in the ribotype cycling back to healthcare settings. Durability of $C$. difficile spores in hospital settings should also favor increased virulence, and accordingly ribotypes associated with outbreaks and severe disease were some of the most efficient and prolific at sporulation (Akerlund et al. 2008, Merrigan et al. 2010, Vohra and Poxton 2011, Vohra et al. 2012).

This study has demonstrated that attendant-borne transmission as well as the persistence and durability of certain $C$. difficile ribotypes in healthcare environments are associated with the observed increase in virulence of nosocomial ribotypes relative to community ribotypes over the past thirty years. The independent emergence of several clinically-relevant strains $(027,001,106$, and 078) associated with increased severity of disease and responsible for multiple $C$. difficile outbreaks in such a short evolutionary 
timeframe (He et al. 2010) also suggests that selective pressures, such as those provided by attendant-borne transmission, have played an important role in the observed increase of $C$. difficile morbidity and mortality.

In order to gain a more comprehensive understanding of the disease ecology and evolution of Clostridium difficile virulence, there remain many aspects of the organism's life cycle and pathogenicity that must be evaluated. More detailed prospective studies that include asymptomatic carriers and combine epidemiological approaches with isolate typing would be helpful for further evaluating the role of attendantborne transmission and how asymptomatic carriers may contribute to the cycling of nosocomial ribotypes in the outside community. Understanding the role of various $C$. difficile virulence factors, host immunity factors, and antibiotics of in the transmission and pathogenicity of $C$. difficile through an evolutionary context could also contribute to efforts aimed at preventing the emergence of highly virulent strains.

\section{Virulence Factors}

Clostridium difficile's primary mechanism of virulence has been thought to be the production of an enterotoxin and cytotoxin, known respectively as TcdA and TcdB, but now the picture seems much less clear (Deneve et al. 2009). Initially it was believed that TcdA, which has been linked to fluid accumulation and inflammation, was responsible for the majority of $C$. difficile-related disease. TcdA has also been demonstrated to increase the permeability of colonic epithelial layers through disruption of tight junctions in cases of pseudomembranous colitis (Voth and Ballard 2005). However recent studies have shown that TcdA- $C$. difficile such as ribotype 017 are capable of causing CDAD, and it appears that both TcdA and TcdB can trigger cell apoptosis albeit through different pathways (Voth and Ballard 2005). TcdB is now believed to be the more potent toxin of the two due to its higher rate of enzymatic activity and ability to cause a great deal of damage to the intestinal epithelium in a relatively short amount of time (Voth and Ballard 2005). The majority of the clinically-relevant strains discussed in this paper and listed in Table 3 are known to produce both TcdA and TcdB, but there are many other factors associated with toxin production that could contribute to virulence, including duration of toxin production, quantity of toxins 
produced, and perhaps even host factors. Several important intrinsic virulence factors of $C$. difficile are listed below in Table 4 .

\begin{tabular}{|c|c|c|}
\hline Type & Description \& Function & References \\
\hline $\operatorname{TcdA}$ & $\begin{array}{l}\text { An enterotoxin that acts on enterocytes by disrupting proteins } \\
\text { involved in actin organization and maintenance of tight junctions, } \\
\text { leading to an increase in the permeability of colonic epithelial } \\
\text { layers, fluid accumulation, cell-rounding, and often apoptosis. }\end{array}$ & Voth and Ballard 2005 \\
\hline TcdB & $\begin{array}{l}\text { A cytotoxin that disrupts signal transduction mechanisms, leading } \\
\text { to inactivation of GTP-binding proteins and causing actin } \\
\text { cytoskeleton disorganization. This can eventually cause actin } \\
\text { condensation, cell rounding, and apoptosis. TcdB exhibits a higher } \\
\text { rate of enzymatic activity than TcdA, giving it the ability to } \\
\text { damage the intestinal epithelium cytopathic more quickly than } \\
\text { TcdA. }\end{array}$ & Voth and Ballard 2005 \\
\hline $\begin{array}{l}\text { Binary toxin } \\
\text { CDT }\end{array}$ & $\begin{array}{l}\text { An ADP ribosyltransferase that induces structural changes in } \\
\text { enterocyte microtubules, resulting in cell membrane protrusions } \\
\text { that wrap and embed } C \text {. difficile into the cell membrane; aids in } \\
\text { adherence to the intestinal walls }\end{array}$ & Schwan et al. 2009 \\
\hline CdtR & $\begin{array}{l}\text { A regulatory protein coded for by the } c d t R \text { gene that is needed for } \\
\text { optimal binary toxin production }\end{array}$ & Carter et al. 2007 \\
\hline TcdC & $\begin{array}{l}\text { A regulatory protein that inhibits TcdA and TcdB production (An } \\
18 \mathrm{bp} \text { deletion and a } 39 \mathrm{bp} \text { deletion in ribotype } 027 \text { 's } t c d C \text { gene is } \\
\text { thought to produce an inactive form of TcdC, leading to increased } \\
\text { levels of TcdA and TcdB). }\end{array}$ & $\begin{array}{l}\text { Curry et al. } 2006 \\
\text { Dupuy et al. } 2008\end{array}$ \\
\hline $\begin{array}{l}\text { Adhesin } \\
\text { proteins }\end{array}$ & Cwp66 protein helps $C$. difficile to adhere to enterocytes & Waligora et al. 2001 \\
\hline Flagella & $\begin{array}{l}\text { Allow for greater adherence to enterocytes and may play a role in } \\
\text { subverting host immune defenses }\end{array}$ & $\begin{array}{l}\text { Stabler et al. } 2009 \\
\text { Tasteyre et al. } 2001\end{array}$ \\
\hline Fimbriae & May play a role in adherence but requires further study & Borriello et al. 1988 \\
\hline
\end{tabular}

Epidemic ribotype 027 's toxin production regulatory mechanisms have been studied with the hope of discovering why this particular ribotype is capable of causing such severe disease. Several mutations in the $t c d C$ gene, which codes for the TcdC regulatory protein, are thought to contribute to the production of a faulty $\mathrm{TcdC}$ protein, allowing 027 to continue producing toxins at high levels during its life cycle long after most ribotypes have reduced toxin output (Curry et al. 2006, Dupuy et al. 2008, Saxton et al. 2009, Merrigan et al. 2010). Ribotype 027 also possesses the ability to produce an additional toxin known as 
binary toxin $\mathrm{CDT}$, which is able to induce actin rearrangement in enterocytes, creating cell membrane protrusions that envelope $C$. difficile. This process is believed to aid 027 in adhering to the intestinal epithelium, which is required in order for $C$. difficile to cause disease (Schwan et al. 2009). CDT+ strains have been linked with greater disease severity, and not surprisingly, the ability to produce CDT has been on the rise in ribotype 027 isolates, with the incidence of CDT+ isolates climbing upwards of $40 \%$ in the United Kingdom (Stabler et al. 2009). Some ribotype 078 isolates have been reported to produce CDT as well and to exhibit highly virulent characteristics similar to epidemic ribotype 027 (Goorhuis et al. 2008).

Interestingly, the presence or absence of certain amino acids has been found to affect $C$. difficile toxin yields in vitro which raises the question of the role of competition between gut bacteria for resources in virulence regulation. A study of gnotic mice colonized with VPI 10463/ribotype 087 (a strain known for high toxin production but isn't typically nosocomial) reported that a change of diet reduced fecal TcdA yields by up to 100 -fold without affecting bacterial numbers, and the mortality due to $C$. difficile decreased significantly (Mahe et al. 1987). Additionally, an in vivo reduction in pathology was also observed when colonizing strains of E. coli and Bifidobacterium bifidum were introduced, leading to decreased cytotoxin yields from the VPI 10463/ribotype 087 strain (Corthier and Muller 1988). VPI 10463/ribotype 087 is known to have high toxin yields but is not known to sporulate well, leading some to suggest that the decrease in toxin production could signify a shift in survival strategies in response to competition (Akerlund et al. 2006). Similar studies conducted with highly virulent, spore-producing ribotypes could be useful for clarifying the role of interspecific competition for resources on the virulence of different $C$. difficile strains.

Adherence factors such as adhesin proteins, flagella, and fimbriae have historically received less attention than the various toxins of $C$. difficile, but they may play a significant role in both colonization and virulence. One adhesin protein known as Cwp66 has been demonstrated to help C. difficile adhere to enterocytes and is a target of antibodies (Waligora et al. 2001). In addition to granting motility, C. difficile flagella also enable the bacteria to better adhere to enterocytes and possibly subvert host defenses, leading to increased colonization success (Tasteyre et al. 2001, Stabler et al. 2009). Fimbriae have also been 
implicated as possible mechanism through which $C$. difficile could increase its adhesion abilities, but so far there have been few studies, with most being inconclusive (Borriello et al. 1988). Further studies on adhesion mechanisms, particularly those of highly virulent ribotypes, could identify potential targets for new antimicrobials that could then be used to prevent the adhesion of $C$. difficile to the intestinal epithelium.

\section{Role of Antibiotic Therapy}

As previously mentioned, antibiotic exposure is thought to play a crucial role in the majority of $C$. difficile cases by causing dysbiosis and compromising the colonization barrier (Deneve et al. 2008). Until recently, little attention has been paid to other potential effects of antibiotics on the regulation of $C$. difficile virulence factors. New evidence suggests that certain antibiotics may act as a stimulus or inducer signaling for the increase in production of virulence factors and spores. One study demonstrated that fluoroquinolones can induce increased spore germination and toxin production in ribotypes 027 and 001 in a human gut model (Saxton et al. 2009). Toxin production was also shown to be increased and to begin earlier in four C. difficile strains exposed to sub-inhibitory levels of metronidazole, vancomycin, linezolid (Gerber et al. 2008). Toxin production and sporulation are not the only virulence-related functions affected by antibiotics; genes encoding for three different adherence factors are also reportedly upregulated in the presence of sublethal levels of clindamycin and ampicillin as well (Deneve et al. 2008). The implications of these findings could prove to be extremely important to reducing antimicrobial-associated CDI, for creating policies guiding antibiotic use during $C$. difficile outbreaks, and for the production of new antimicrobials that $C$. difficile is both susceptible to and unlikely to produce excess virulence factors in response to treatment with them.

\section{Host Factors}

Variations in host immunity are a relatively new consideration in the investigation of CDI risk factors, but they could prove to be important for understanding infection in asymptomatic carriers. A prospective study of 810 patients admitted to the Minneapolis Veterans Affairs Medical Center and the 
New England Deaconess Hospital found that the 192 identified asymptomatic carriers were less likely to develop CDAD during their stay compared with non-carriers (1.0\% vs. $3.6 \%)$. Even with the addition of CDAD risk factors like treatment with antibiotics, asymptomatic carriers still had a lower CDAD rate (1.1\% vs. 4.5\%) compared to non-colonized individuals (Shim et al. 1998). Whether this represents some sort of host-immune interaction and subsequently conferred immunity to $C$. difficile-related illness is unclear, but it does suggest that most hospital patients diagnosed with CDAD are not falling ill from their own native C. difficile flora after receiving antibiotic therapy. The difference between the rates of CDAD in noncolonized individuals versus non-colonized individuals who received antibiotic therapy (3.6\% vs. $4.5 \%)$ was minimal, suggesting that treatment with antibiotics might not be the most significant risk factor for CDAD in a hospital setting despite antibiotics being thought to disrupt the native intestinal microbiota (Deneve et al. 2008). Alternatively, colonization status prior to admission and in particular, colonization with particularly pathogenic nosocomial strains after admission could play a significant role in the development of CDAD. Further studies are needed to evaluate this possibility and to fully explain the role of host immune factors in determining what distinguishes individuals who become symptomatic when colonized with $C$. difficile from those who remain healthy as carriers.

\section{Implications for Public Health}

Examining the spread of $C$. difficile in hospitals and other healthcare settings within an evolutionary context could provide new insights and useful tools for stopping its spread and manipulating the virulence of some of the more deadly nosocomial strains into milder ones. Attendant-borne transmission is easily preventable when the proper protocol is established and followed consistently in healthcare settings. One study that evaluated the efficacy of regular glove use when encountering CDI patients demonstrated significantly reduced CDI incidence and asymptomatic infections in comparison to control wards (Johnson

et al. 1990). Since alcohol-based hand sanitizers are ineffective at killing $C$. difficile spores, it is also important that hand washing with soap and water and/or a chlorine agent is performed after coming into contact with a CDI patient or wards where CDI patients reside (Gerding et al. 2008). This is equally as 
important in hospitals as it is in long-term care facilities, where skin and environmental contamination are common (Riggs et al. 2007). Implementing the use of gloves by all healthcare personnel when attending to C. difficile infected patients, reminding staff to use hot water and soap to wash their hands after working with CDAD patients, and educating hospital visitors and all personnel on the need for glove use and/or washing hands with soap or chlorine agents is essential to any successful infection control campaign that seeks to prevent attendant-borne transmission.

Eliminating spores and preventing $C$. difficile's ability to persist on hospital surfaces is also crucial to any plan for reducing the virulence and incidence of CDIs. A 2007 study conducted among long-term care facility residents found that even asymptomatic carriers of $C$. difficile had a high rate of skin (61\%) and environmental contamination (59\%). $87 \%$ of isolates from skin swabs and $58 \%$ of isolates from environmental surfaces matched strain types found concurrently in resident fecal samples. Additionally, spores from the residents' skin were found to be easily transferred to the investigators' hands, which could increase attendant-borne transmission and further contribute to the emergence of highly virulent variants (Riggs et al. 2007). C. difficile spores are capable of persisting on hospital environmental surfaces for up to 5 months (Kim et al. 1981), and epidemic strains have been shown to actually increase sporulation in response to exposure to ineffective disinfectants (i.e. non-chlorine-based cleaning agents), meaning that infection control measures such as thoroughly cleaning frequently contacted surfaces and rooms of CDAD patients may be counterproductive to controlling or preventing $C$. difficile outbreaks if the proper sanitization procedures are not being used (Wilcox and Fawley 2000). Rooms of CDAD patients must be thoroughly cleaned using 10\% sodium hypochlorite for all spores to be eliminated (Gerding et al. 2008). Ultimately such steps should negate the fitness advantages associated with host exploitation by durable, attendant-borne $C$. difficile. Consequently, mild strains should be evolutionarily favored.

Reducing attendant-borne transmission of Clostridium difficile should also help to reduce the incidence of antibiotic-resistant strains seen in hospitals. When governed by proper stewardship protocols, antibiotics are typically only administered when disease is severe, which is often associated with highly 
virulent organisms. Logic would suggest that virulent strains of $C$. difficile that greatly exploit their hosts and therein by cause severe symptoms tend to be the strains most frequently treated with antibiotics and the strains most likely to cause a patient to seek treatment in a hospital setting. Accordingly, attendant-borne transmission should favor these highly virulent, highly exploitative strains that tend to most often require antibiotics. If attendant-borne transmission is reduced, incidence of these severe infections is reduced, and the need for treating these severe infections with antibiotics is also reduced. Administering fewer antibiotics to treat these infections should lessen the probability that a particular strain will be exposed to and subsequently develop resistance to a given antibiotic.

Finally, improving surveillance for CDI and particularly for asymptomatic CDI in healthcare settings could help prevent further outbreaks and alert healthcare institutions to the presence of $C$. difficile potentially before symptomatic cases begin to appear. Typing of strains needs to be established as a regular diagnostic protocol along with antibiotic susceptibility testing, so as to minimize resistance and to raise the attention of hospital staff if individuals harboring particularly virulent $C$. difficile variants, especially those known for robust spore production, are admitted. One of the reasons proposed for the sharp decline observed in ribotype 027 CDIs since late 2007 in the United Kingdom has been the implementation of mandatory reporting along with making typing of $C$. difficile isolates widely available to healthcare providers through the Clostridium difficile Ribotyping Network (established in 2007) and strictly limiting the use of antibiotics associated with CDI (Cairns et al. 2012, Wilcox et al. 2012). Lack of continuity and consistency between the use of typing techniques, definitions with respect to community-associated CDI, and definitions for what constitutes a healthcare exposure are issues that limit the accessibility of studies and hinder scientific collaboration across regions (Freeman et al. 2010). Establishing and implementing global standards for optimal isolate typing techniques, definitions for CDI, definitions for healthcare exposures would facilitate international efforts for $C$. difficile epidemiological tracking and contribute to the creation of a unified understanding of Clostridium difficile variation, biology, and pathology. 


\section{ACKNOWLEDGEMENTS}

I would like to thank my thesis mentor, Dr. Paul Ewald, for his patient guidance, enthusiastic

encouragement and useful critiques of this research work.

\section{REFERENCES}

Akerlund, T., I. Alefjord, U. Dohnhammar, J. Struwe, T. Norén and K. Tegmark-Wissell (2011). "Geographical Clustering of Cases of Infection with Moxifloxacin-Resistant Clostridium difficile PCR-Ribotypres 012, 017, and 046 in Sweden, 2008 and 2009." Eurosurveillance 16(10)

Akerlund, T., I. Persson, M. Unemo, T. Norén, B. Svenungsson, M. Wullt and L. G. Burman (2008). "Increased Sporulation Rate of Epidemic Clostridium difficile Type 027/NAP1." Journal of Clinical Microbiology 46(4): 1530-1533.

Akerlund, T., B. Svenungsson, A. Lagergren and L. G. Burman (2006). "Correlation of Disease Severity with Fecal Toxin Levels in Patients with Clostridium difficile-associated Diarrhea and Distribution of PCR Ribotypes and Toxin Yields In Vitro of Corresponding Isolates." Journal of Clinical Microbiology 44(2): 353-358.

Baines, S. D., J. Freeman and M. H. Wilcox (2005). "Effects of Piperacillin/tazobactam on Clostridium difficile Growth and Toxin Production in a Human Gut Model." Journal of Antimicrobial Chemotherapy 55(6): 974-982.

Barbut, F., G. Corthier, Y. Charpak, M. Cerf, H. Monteil and T. Fosse (1996). "Prevalence and Pathogenicity of Clostridium difficile in Hospitalized Patients." Archives of Internal Medicine 156: 1449-1454.

Bartlett, J. G. (2006). "Narrative Review: The New Epidemic of Clostridium difficile - Associated Enteric Disease." Annals of Internal Medicine 145(10): 758-764.

Bauer, M. P., D. W. Notermans, B. H. B. van Benthem, M. H. Wilcox, D. I. Monnet, J. T. van Diesel and E. J. Kuijper (2009). First Results of the European Clostridium difficile Infection Survey (ECDIS). 19th European Congress of Clinical Microbiology and Infectious Diseases, Helsinki, Finland.

Borriello, S. P., H. A. Davies and F. E. Barclay (1988). "Detection of Fimbriae amongst Strains of Clostridium difficile." FEMS Microbiology Letters 49: 65-67.

Boyer, K. M., N. J. Peterson, C. P. Pattison, M. C. Hart and J. E. Maynard (1975). "An Outbreak of Gastroenteritis Due to E. coli 0142 in a Neonatal Nursery." Journal of Pediatrics 86: 919-927.

Cairns, M., R. A. Stabler, N. Shefty and B. Wren (2012). "The Continually Evolving Clostridium difficile Species." Future Microbiology 7(8): 945-957.

Cheknis, A. K., S. P. Sambol, D. M. Davidson, K. J. Nagaro, M. C. Mancini, G. A. Hidalgo-Arroyo, J. S. Brazier, S. Johnson and D. N. Gerding (2009). "Distribution of Clostridium difficile Strains from a North American, European and Australian Trial of Treatment for C. difficile Infections: 2005-2007." Anaerobe 15(6): 230233.

Chimalizeni, Y., K. Kawaza and E. Molyneux (2010). "The Epidemiology and Management of Non-typhoidal Salmonella Infections." Advances in Experimental Medicine and Biology 659: 33-46.

Clabots, C. R., S. Johnson, M. M. Olson, L. R. Peterson and D. N. Gerding (1992). "Acquisition of Clostridium difficile by Hospitalized Patients: Evidence for Colonized New Admissions as a Source of Infection." Journal of Infectious Diseases 166(3): 561-567.

Cohen, S. H., D. N. Gerding and S. Johnson (2010). "Clinical Practice Guidelines for Clostridium difficile Infection in Adults: 2010 Update by the Society for Healthcare Epidemiology of America (SHEA) and the Infectious Diseases Society of America (IDSA)." Journal of Infection Control and Hospital Epidemiology 31: 431455 . 
Cooper, B. S., G. F. Medley and G. M. Scott (1999). "Preliminary Analysis of the Transmission Dynamics of Nosocomial Infections: Stochastic and Management Effects." Journal of Hospital Infection 43(2): 131-147.

Cooper, M. L., E. W. Walters and H. M. Keller (1956). "E. coli Associated with Infantile Diarrhea." Annals of the New York Academy of Science 66: 78-89.

Corthier, G. and M. C. Muller (1988). "Emergence in Gnotobiotic Mice of Nontoxinogenic Clones of Clostridium difficile from a Toxinogenic One." Infection and Immunity 56(6): 1500-1504.

Curry, S. R., J. W. Marsh, C. A. Muto, M. M. O'Leary, A. W. Pasculle and L. H. Harrison (2006). "tcdC Genotypes Associated with Severe TcdC Truncation in an Epidemic Clone and Other Strains of Clostridium difficile." Journal of Clinical Microbiology 45(1): 215-221.

Deneve, C., C. Delomenie, M. Barc, A. Collignon and C. Janoir (2008). "Antibiotics Involved in Clostridium difficile-associated Disease Increase Colonization Factor Gene Expression." Journal of Medical Microbiology 57(6): 732-738.

Deneve, C., C. Janoir, I. Poilane, C. Fantinato and A. Collignon (2009). "New Trends in Clostridium difficile Virulence and Pathogenesis." International Journal of Antimicrobial Agents 33(1): 24-28.

Dubberke, E. R., K. A. Reske, M. A. Olsen, L. C. McDonald and V. J. Fraser (2008). "Short-and Long-term Attributable Costs of Clostridium difficle-associated Disease in Nonsurgical Inpatients." Journal of Clinical Infectious Diseases 46(4): 497-504.

Dumyati, G., V. Stevens, G. E. Hannett, A. Thompson, C. M. Long, D. McCannell and B. M. Limbago (2012). "Community-associated Clostridium difficile Infections, Monroe County, New York, USA." Emerging Infectious Diseases 18(3): 392-400.

Dupuy, B., R. Govind, A. Antunes and S. Matamouros (2008). "Clostridium difficile toxin synthesis is negatively regulated by TcdC." Journal of Medical Microbiology 57(6): 685-689.

Ewald, P. W. (1988). Cultural Vectors, Virulence, and the Emergence of Evolutionary Epidemiology. 5: 215-245.

Ewald, P. W. (1991). "Transmission Modes and the Evolution of Virulence, with Special Reference to Cholera, Influenza and AIDS." Human Nature 2: 1-30.

Fekety, R., K. H. Kim, D. Brown, D. H. Batts, M. Cudmore and J. J. Silva (1981). "Epidemiology of Antibioticassociated Colitis; Isolation of Clostridium difficile from the Hospital Environment." American Journal of Medicine 70(4): 906-908.

Freeman, J., M. P. Bauer, S. D. Baines, J. Corver, F. W.N., B. Goorhuis, E. J. Kuijper and W. M. H. (2010). "The Changing Epidemiology of Clostridium difficile Infections." Clinical Microbiology Reviews 23(3): 529549.

Gerber, M., C. Walch, D. Loffler and K. Tischendorff (2008). "Effect of sub-MIC Concentrations of Metronidazole, Vancomycin, Clindamycin and Linezolid on Toxin Gene Transcription and Production in Clostridium difficile." Journal of Medical Microbiology 57(6): 776-783.

Gerding, D. N. (2004). "Clindamycin, Cephalosporins, Fluoroquinolones, and Clostridium difficile-Associated Diarrhea: This Is an Antimicrobial Resistance Problem." Clinical Infectious Disease 38(5): 646-648.

Gerding, D. N., C. A. Muto and R. C. J. Owens (2008). "Measures to Control and Prevent Clostridium difficile Infection." Journal of Clinical Infectious Diseases 15(46): 43-49.

Goorhuis, A., D. Bakker, J. Corver, S. DeBast and D. W. Notermans (2008). "Emergence of Clostridium difficile Infection Due to a New Hypervirulent Strain, Polymerase Chain Reaction Ribotype 078." Clinical Infectious Disease 47(9): 1162-1170.

Goorhuis, A., T. Van der Kooi, N. Vaessen, F. W. Dekker, R. Van den Berg, C. Harmanus, S. van den Hof, D. W. Notermans and E. J. Kuijper (2007). "Spread and Epidemiology of Clostridium difficle Polymerase Chain Reaction Ribotype 027/Toxinotype III in The Netherlands." Journal of Clinical Infectious Diseases 45: 695-703.

Gravel, D., M. Miller, A. Simor, G. Taylor, M. Gardam, A. McGeer, J. Hutchinson, D. Moore, S. Kelly, D. Boyd and M. Mulvey (2009). "Health care-associated Clostridium difficile Infection in Adults Admitted to Acute Care Hospitals in Canada: a Canadian Nosocomial Infection Surveillance Program Study." Journal of Clinical Infectious Diseases 48(5): 568-576.

Harbarth, S., H. Sax and P. Gastmeier (2003). "The Preventable Proportion of Nosocomial Infections: an Overview of Published Reports." Journal of Hospital Infection 54(4): 258-266.

He, M., M. Sebaihia, T. D. Lawley, R. A. Stabler, L. Dawson, M. Martin and K. E. Holt (2010). "Evolutionary Dynamics of Clostridium difficile Over Short and Long Time Scales." Proceedings of the National Academy of Sciences of the United States of America.

Jacobs, S. I., A. Holzel, B. Wolman, J. H. Keen, V. Miller, J. Taylor and R. J. Gross (1970). "Outbreak of Infantile Gastroenteritis Caused by Escherichia coli 0114." Archives of Disease in Childhood 45: 656-663. 
Jameson, J. E., T. P. Mann and N. J. Rothfield (1954). "Hospital Gastroenteritis, an Epidemiological Survey of Infantile Diarrhea and Vomiting Contracted in Children's Hospital." The Lancet: 459-465.

Janezic, S., M. Ocepek, V. Zidaric and M. Rupnik (2012). "Clostridium difficile Genotypes Other Than Ribotype 078 that are Prevalent Among Human, Animal and Environmental Isolates." BMC Microbiology 12(48).

Johnson, S., D. N. Gerding, M. M. Olson, M. D. Weiler and R. A. Hughes (1990). "Prospective, Controlled Study of Vinyl Glove Use to Interrupt Clostridium difficile Nosocomial Transmission." American Journal of Medicine 88(2): 137-140.

Jump, R. L., M. J. Pultz and C. J. Donskey (2007). "Vegetative Clostridium difficile Survives in Room Air on Moist Surfaces and in Gastric Contents with Reduced Acidity: a Potential Mechanism to Explain the Association Between Proton Pump Inhibitors and $C$. difficile-associated Diarrhea?" Antimicrobial Agents and Chemotherapy 51(8): 2883-2887.

Kato, H., H. Kita, T. Karasawa and T. Maegawa (2001). "Colonization and Transmission of Clostridium difficile in Healthy Individuals Examined by PCR Ribotyping and Pulsed-Field Gel Electrophoresis." Journal of Medical Microbiology 50: 720-727.

Keel, K., J. S. Brazier, K. W. Post, S. Weese and J. G. Songer (2007). "Prevalence of PCR Ribotypes among Clostridium difficile Isolates from Pigs, Calves, and Other Species ${ }^{\nabla} . "$ Journal of Clinical Microbiology 45(6): 1963-1964.

Khanna, S. and D. S. Pardi (2010). "The Growing Incidence and Severity of Clostridium difficile Infection in Inpatient and Outpatient Settings." Expert Reviews in Gastroenterology and Hepatology 4(4): 409-416.

Kim, K. H., R. Fekety, D. H. Batts, D. Brown, M. Cudmore, J. J. Silva and D. Waters (1981). "Isolation of Clostridium difficile from the Environment and Contacts of Patients with Antibiotic-Associated Colitis." Journal of Infectious Diseases 143(1): 42-50.

Knittle, M. A., D. V. Eitzman and H. Baer (1975). "Role of Hand Contamination of Personnel in the Epidemiology of Gram-Negative Nosocomial Infections." Journal of Pediatrics 86: 433-437.

Kohler, P. F. (1964). "Hospital Salmonellosis: A Report of 23 Cases of Gastroenteritis Caused by Salmonella infantis." Journal of the American Medical Association 189(1): 6-10.

Limbago, B. M., C. M. Long, A. Thompson, G. E. Killgore, G. E. Hannett, N. L. Havill and S. Mickelson (2009). "Clostridium difficile Strains from Community-Associated Infections $\nabla$. " Journal of Clinical Microbiology 47(9): 3004-3007.

Mackerras, I. M. and M. J. Mackerras (1949). "An Epidemic of Infantile Gastroenteritis in Queensland caused by Salmonella bovis-morbificans." Journal of Hygiene 47(2): 166-181.

Mahe, S., G. Corthier and F. Dubos (1987). "Effect of Various Diets on Toxin Production by Two Strains of Clostridium difficile in Gnotobiotic Mice." Infection and Immunity 55(8): 1801-1805.

McDonald, B. C., S. Banerjee and D. B. Jernigan (2004). Increasing Incidence of Clostridium difficile-associated Disease in US Acute Care Hospitals, 1993-2001. 14th Annual Scientific Meeting of the Society for Healthcare Epidemiology in America, Philadelphia.

McDonald, L. C., G. E. Killgore, A. Thompson, R. C. Owens, S. V. Kazavoka, S. P. Sambol, S. Johnson and D. N. Gerding (2005). "An Epidemic, Toxin Gene-Variant Strain of Clostridium difficile." The New England Journal of Medicine 353: 2433-2441.

McDonald, L. C., F. Lessa, D. Sievert, M. Wise, R. Herrera, C. Gould, P. Malpiedi, M. Dudeck, A. Srinivasan, S. Fridkin and D. Cardo (2012). "Vital Signs: Preventing Clostridium difficile Infections." Morbidity and Mortality Weekly Report 61(9): 157-161.

Merrigan, M., A. Venugopal, M. Mallozzi, B. Roxas, V. S. Viswanthan, S. Johnson, D. N. Gerding and G. Vedantam (2010). "Human Hypervirulant Clostridium difficile Strains Exhibit Increased Sporulation as Well as Robust Toxin Production." Journal of Bacteriology 192: 4904-4911.

Miyajima, F., A. P. Roberts, A. Swale, V. Price, M. Jones, M. Horan and N. Beeching (2011). "Characterisation and Carriage Ratio of Clostridium difficile Strains Isolated from a Community-Dwelling Elderly Population in the United Kingdom." PloS One 6(8).

Mushin, R. (1948). "An Outbreak of Gastroenteritis Due to Salmonella derby." Journal of Hygiene 46(2): 151-157.

Norén, T., T. Akerlund, E. Back, L. Sjoberg, I. Persson, I. Alriksson and L. G. Burman (2004). "Molecular Epidemiology of Hospital-Associated and Community-Acquired Clostridium difficile Infection in a Swedish County." Journal of Clinical Microbiology: 3635-3643.

Pamer, E. G. (2013). Clostridium difficile Infection. Memorial Sloan-Kettering Cancer Center.

Pepin, J., L. Valiquette and M. E. Alary (2004). "Clostridium difficle-associated Diarrhea in a Region of Quebec from 1991 to 2003: a Changing Pattern of Disease Severity." Canadian Medical Association Journal 171: 466-472. 
Razavi, B., A. Apisarnthanarak and L. M. Mundy (2007). "Clostridium difficile: Emergence of Hypervirulence and Fluoroquinolone Resistance." Infection 35: 300-304.

Redelings, M. D., F. Sorvillo and L. Mascola (2007). "Increase in Clostridium difficile-related Mortality Rates, United States, 1999-2004." Journal of Emerging Infectious Disease 9: 1417-1419.

Riggs, M. M., A. K. Sethi, T. F. Zabarsky, E. C. Eckstein, R. L. Jump and C. J. Donskey (2007). "Asymptomatic Carriers are a Potential Source for Transmission of Epidemic and Nonepidemic Clostridium difficile Strains among Long-term Care Facility Residents." Journal of Clinical Infectious Diseases 45(8): 992-998.

Rubbo, S. D. (1948). "Cross-infection in Hospital Due to Salmonella derby." Journal of Hygiene 46: 158-163.

Samore, M. H., L. Venkataraman, P. C. DeGirolami, R. D. Arbeit and A. W. Karchmer (1996). "Clinical and Molecular Epidemiology of Sporadic and Clustered Cases of Nosocomial Clostridium difficile Diarrhea." American Journal of Medicine 100(1): 32-40.

Sawabe, E., H. Kato, K. Osawa, T. Chida, N. Tojo, Y. Arakawa and N. Okamura (2007). "Molecular Analysis of Clostridium difficile at a University Teaching Hospital in Japan: A Shift in the Predominant Type Over a Five-year Period." European Journal of Clinical Microbiology and Infectious Diseases 26(10): 695-703.

Saxton, K., S. Baines, J. Freeman and R. O'Connor (2009). "Effects of Exposure of Clostridium difficile PCR Ribotype 027 and 001 to Fluoroquinolones in a Human Gut Model." Antimicrobial Agents and Chemotherapy 53(2): 412-420.

Schwan, C., B. Stecher, T. Tzivelekidis, M. von Ham, M. Rohde, W. Hardt, J. Wehland and K. Aktories (2009). "Clostridium difficile Toxin CDT Induces Formation of Microtubule-Based Protrusions and Increases Adherence of Bacteria." PLoS Pathogens 5(10).

Sethi, A. K., W. N. Al-Nassir, N. M. M., G. S. Bobulsky and C. J. Donskey (2010). "Persistence of Skin Contamination and Environmental Shedding of Clostridium difficile During and After Treatment of $C$. difficile Infection." Journal of Infection Control and Hospital Epidemiology 31(1): 21-27.

Settle, C. D., M. H. Wilcox, W. N. Fawley, O. J. Corrado and P. M. Hawkey (1998). "Prospective Study of the Risk of Clostridium difficile Diarrhoea in Elderly Patients Following Treatment with Cefotaxime or Piperacillintazobactam." Alimentary Pharmacology and Therapeutics 12(12): 1217-1223.

Sheth, P. M. (2013). Evidence of Clostridium difficile in Asymptomatic Patients. 23rd European Congress of Clinical Microbiology and Infectious Diseases (ECCMID), Berlin, Germany.

Shim, J. K., S. Johnson, M. H. Samore, D. Z. Bliss and D. N. Gerding (1998). "Primary Symptomless Colonization by Clostridium difficile and Decreased Risk of Subsequent Diarrhoea." The Lancet 351: 633-636.

Shinefield, H. R. (1976). Staphylococcal Infections. Infectious Diseases of the Fetus and Newborn Infant. J. S. K. Rempton, J. O. Philadelphia, Pennsylvania, W.B. Saunders.

Stabler, R. A., M. He, L. Dawson, M. Martin, E. Valiente and C. Corton (2009). "Comparative Genome and Phenotypic Analysis of Clostridium difficile 027 Strains Provides Insight into the Evolution of a Hypervirulent Bacterium." Genome Biology 10(9): 102.

Stubbs, S. L., J. S. Brazier, G. L. O'Neill and B. I. Duerdan (1999). "PCR Targeted to the 16S-23S rRNA Gene Intergenic Spacer Region of Clostridium difficile and Construction of a Library Consisting of 116 Different PCR Ribotypes." Journal of Clinical Microbiology 37(2): 461-463.

Tasteyre, A., M. Barc and T. Karjalainen (2001). "Role of FliC and FliD Flagellar Proteins of Clostridium difficile in Adherence and Gut Colonization." Infection and Immunity 69(12): 7937-7940.

Voelker, R. (2010). "Increased Clostridium difficile Virulence Demands New Treatment Approach." Journal of the American Medical Association 303(20): 2017-2019.

Vohra, P. and I. R. Poxton (2011). "Comparison of Toxin and Spore Production in Clinically Relevant Strains of Clostridium difficile." Microbiology 157: 1343-1353.

Vohra, P., I. R. Poxton and D. Gally (2012). Clostridium difficile: Expression of Virulence Factors, Resistance to Disinfectants and Interactions with Human Cells. PhD, University of Edinburgh.

Voth, D. E. and J. D. Ballard (2005). "Clostridium difficile Toxins: Mechanism of Action and Role in Disease." Clinical Microbiology Reviews 18(2): 247-263.

Waligora, A., C. Hennequin and T. Karjalainen (2001). "Characterization of a Cell Surface Protein of Clostridium difficile with Adhesive Properties." Infection and Immunity 69(4): 2144-2153.

Walther, B. W. and P. W. Ewald (2004). "Pathogen Survival in the External Environment and the Evolution of Virulence." Biological Reviews of the Cambridge Philosophical Society 79(4): 849-869.

Wilcox, M. H. and W. N. Fawley (2000). "Hospital Disinfectants and Spore Formation by Clostridium difficile." The Lancet 356(9238): 1324.

Wilcox, M. H., N. Shefty, W. N. Fawley, M. Shemko, P. Coen, A. Birtles, M. Cairns, M. D. Curran, K. J. Dodgson and e. al. (2012). "Changing Epidemiology of Clostridium difficile Infection Following the Introduction of 
a National Ribotyping-based Surveillance Scheme in England." Journal of Clinical Infectious Diseases 55(8): 1056-1063.

Zidaric, V., B. Pardon, T. Dos Vultos, P. Deprez, M. S. Brouwer, A. P. Roberts, H. A. O. and M. Rupnik (2012). "Different Antibiotic Resistance and Sporulation Properties within Multiclonal Clostridium difficile PCR ribotypes 078, 126, and 033 in a Single Calf Farm." Applied and Environmental Microbiology 78(24): 8515-8522.

Zilberberg, M. D., A. F. Shorr and M. H. Kollef (2008). "Increase in Clostridium difficile-related Hospitalizations and Case-Fatality Rate, United States, 2000-2005." Emerging Infectious Diseases: 929-931. 